\title{
CONTROLE DA AIDS NO BRASIL: UM MODELO A SER SEGUIDO?
}

O sucesso das políticas de combate e controle da AIDS no Brasil é, hoje, internacionalmente reconhecido. De forma recorrente, a UNAIDS em seus relatórios cita o Brasil como um dos casos bem sucedidos na prevenção e atenção à AIDS. Certamente, esta reputação internacional desempenhou um papel central no desfecho favorável ao Brasil na recente disputa na Organização Mundial de Comércio. Nessa, os Estados Unidos retiraram queixa contra o Brasil por desrespeito à lei de patentes, temendo as repercussões internacionais da continuação do processo, bem como uma eventual perda do mesmo, o que, por sua vez, acarretaria a liberação de uma série de patentes de interesse de laboratórios americanos.

As razões para os resultados favoráveis no controle da AIDS no Brasil podem ser encontradas na política seguida pelo Ministério da Saúde, por meio da Coordenação Nacional de DST/AIDS. Entre as principais características desta política deve-se salientar, em primeiro lugar, a ênfase conjunta na prevenção e na atenção à doença. Outra característica fundamental do modelo brasileiro é o envolvimento de uma ampla gama de setores governamentais e não-governa- mentais, incluindo a participação dos grupos populacionais mais afetados pela epidemia, assim como de indivíduos vivendo com HIV eAIDS. A parceria com distintos segmentos da sociedade civil - igrejas, comunidade científica, organizações não-governamentais, etc. - tem sido a tônica das atividades de controle da AIDS. Quanto aos setores governamentais, cabe ressaltar alguns trabalhos em que o Ministério da Saúde tem se associado a outros Ministérios: usuários de drogas injetáveis (UDI) - Justiça; conscritos do exército - Defesa; alunos e professores - Educação.

No que se refere à prevenção, várias campanhas publicitárias informativas, e outras ações mais focalizadas, determinaram que o país apresentasse um dos menores índices de desconhecimento quanto às formas de proteção entre os países em desenvolvimento. A grande expansão do acesso a preservativos, masculino e feminino, também constitui uma ação importante na área de prevenção. Entre 1986 e 1999, a porcentagem de uso de preservativo na primeira relação sexual cresceu 12 vezes. Cerca de 40 projetos de redução de danos em UDI foram implementados no período 1999-2000, atingindo ao redor de 31.000 usuários, com mais de I,5 milhão de seringas trocadas. Recentemente observou-se, nessa população, queda na prevalência de infecção por HIV. Medidas para prevenção da transmissão vertical do HIV estão atualmente disponíveis em toda a rede pública de saúde.

No que tange a atenção à doença, a ação integrada dos vários níveis do governo, e de várias organizações médicas e não médicas, associada à distribuição gratuita de medicamentos anti-retrovirais, contribuíram de maneira significativa para o reconhecimento internacional do Programa Brasileiro. No final do ano passado, cerca de 95.000 pacientes receberam terapia antiretroviral no sistema público de saúde. Os resultados dessas estratégias foram notáveis. Desde 1996, as taxas de mortalidade e internação de pacientes HIV + vêm mostrando declínio acentuado.

Um estudo do Banco Mundial, no início da década de 90, estimou que no final da década o Brasil deveria registrar algo em torno de I milhão de casos de AIDS. Hoje registramos pouco mais de meio milhão de casos. Os resultados obtidos até agora pelo Brasil permitem concluir que este é um modelo a ser seguido por outros países. 